UDC 539.4

\title{
SCK-CEN Contribution to the IAEA Round Robin Exercise on WWER-440 RPV Weld Material: Irradiation, Annealing, and Re-Embrittlement
}

\author{
E. Lucon, E. van Walle, M. Scibetta, R. Chaouadi, and M. Wéber
}

SCK-CEN, Mol, Belgium

УДК 539.4

Прочность сварных соединений корпусов реакторов ВВЭР-440 в условиях радиационного охрупчивания, отжига и повторного охрупчивания

\author{
Е. Лукон, Е. ван Валле, М. Скибетта, Р. Шоуди, М. Вебер \\ SCK-CEN, Мол, Бельгия
}

Исследованы механические свойства материалов сварных соединений корпусов реакторов ВВЭР-440 с учетом различных состояний: исходного (неохрупченного), после радиационного охрупчивания со средней плотностью потока нейтронов до $6,5 \cdot 10^{19}$ нейтр/см ${ }^{2}$, охрупченного с последуюиим отжигом, повторно охрупченного с флюэнсом частиц $1,3 \cdot 10^{20}$ нейтр/сл ${ }^{2}$. Для каждого состояния материала проведень испьтания на растяжение, ударное разруиение и треииностойкость с использованием образиов НІарпи (стандартные, восстановленные, с предварительно нанесенной трециной).

Ключевые слова: сварное соединение, радиационное охрупчивание, отжиг, повторное охрупчивание, образец.

Introduction. The objective of SCK-CEN in contributing to the IAEA Round-Robin exercise on the WWER-440 weld material was twofold, namely:

1. gaining experience in the field of WWER-440 pressure vessel steels;

2. analyzing Round Robin (R-R) data according to models used and developed at SCK-CEN, in order to check their validity and applicability to this class of steels.

In this paper we present an overview of the activity performed in SCK-CEN during the whole exercise, from 1998 to 2001. More detailed information can be found in [1-3].

Material and Test Matrix. SCK-CEN purchased part 2 of weld No. 502, representative for WWER-440 weld material and identified as block 502.2. The certification report includes information on weld manufacturing, heat treatment, chemical composition and mechanical test results [4]. The cutting scheme of the 502.2-block was made according to the procedure stipulated in the terms of reference, IAEA TC Project RER/9/035 WWER-SC-192 [5].

The specimens extracted were of Charpy-V impact type $(\mathrm{CV})$, precracked Charpy-V (PCCV), tensile (T) and sub-size Charpy-V (MCV, $3 \times 4 \times 27 \mathrm{~mm})$; they 
were subdivided into four groups, each subjected to the same mechanical tests (tensile, impact on standard and sub-size Charpy-V specimens, fracture toughness on $\mathrm{PCCv}$ ):

1. unirradiated (baseline, BL);

2. irradiated (I) in the CHIVAS-7 campaign up to an average neutron fluence of $6.5 \cdot 10^{19} \mathrm{n} / \mathrm{cm}^{2}(E>1 \mathrm{MeV})$;

3. irradiated in CHIVAS-7 and then annealed (IA) as specified in the terms of reference $\left[100\right.$ hours at $\left.(475 \pm 10)^{\circ} \mathrm{C}\right]$;

4. irradiated in CHIVAS-7, annealed and finally re-irradiated (IAR) in the CHIVAS-8 campaign up to an average cumulated fluence of $1.3 \cdot 10^{20} \mathrm{n} / \mathrm{cm}^{2}$ $(E>1 \mathrm{MeV})$.

Irradiations. The irradiations were carried out in the BR2 Material Testing reactor of SCK-CEN in Mol (Belgium). Two campaigns with acronyms CHIVAS-7 and CHIVAS-8 were carried out in the CALLISTO (CApabiLity for Light water Irradiation in Steady state and Transient Operation) loop under PWR conditions. Three separate legs within the loop, so-called in-pile sections (IPS), allow to irradiate up to 162 Charpy-type specimens at the same time.

CHIVAS-7. The first irradiation, which involved 183 specimens, was conducted using two legs (IPS1 and IPS3) of the CALLISTO loop at a temperature of $268^{\circ} \mathrm{C}$ and a pressure of approximately $140 \mathrm{bar}$.

The baskets were rotated in the middle of the irradiation period in order to achieve a uniform fluence on all the specimens; the temperature of the capsule was recorded and found to be $\left(268_{-2}^{+4}\right)^{\circ} \mathrm{C}$. All specimens were in direct contact with circulating water.

The capsule was instrumented with extended dosimetry: three dosimeters, uniquely identified, placed at three levels in 5 of the 9 rods per each leg.

CHIVAS-8. The second irradiation, which involved 78 specimens (60 of which of WWER-440 weld material and the remaining of a different steel), was conducted using one leg (IPS1) of the CALLISTO loop at a temperature of $268^{\circ} \mathrm{C}$ and a pressure of approximately 155 bar.

The baskets were rotated in the middle of the 24-day irradiation cycle in order to achieve a uniform fluence on all specimens; the temperature of the capsule was recorded and found to be $\left(268_{-2}^{+4}\right)^{\circ} \mathrm{C}$. All specimens were in direct contact with circulating water.

As in the case of CHIVAS-7, the capsule was instrumented with extended dosimetry: three dosimeters, uniquely identified, were placed at three levels in 5 of the 9 rods used.

Evaluation of Specimen Fluence. The values of fluence given by the dosimeters placed in every rod were fitted with second-order polynomials, in order to evaluate the fast neutron fluence corresponding to the midplane of every specimen irradiated in the two campaigns.

For rods which were not instrumented with dosimeters, the fluence was calculated using fitting coefficients obtained from the mean of the three adjacent instrumented rods.

The mean fluences and relevant standard deviations reported in Table 1 were calculated for the individual specimen groups. 
E. Lucon, E. van Walle, M. Scibetta, et al.

$\mathrm{T}$ a $\mathrm{b} l \mathrm{e} 1$

Mean Values and Standard Deviations Calculated for the Fluence of the Different Specimen Groups

\begin{tabular}{|c|c|c|c|c|}
\hline Condition & Irradiation & Specimen type & $\begin{array}{l}\text { Mean fluence } \\
\left(\mathrm{n} / \mathrm{cm}^{2}\right)\end{array}$ & $\begin{array}{c}\text { Standard deviation } \\
(\%)\end{array}$ \\
\hline \multirow[t]{4}{*}{ I } & \multirow[t]{4}{*}{ CHIVAS-7 } & $\mathrm{T}$ & $6.5 \cdot 10^{19}$ & 1.8 \\
\hline & & $\mathrm{Cv}$ & $6.6 \cdot 10^{19}$ & 5.6 \\
\hline & & $\mathrm{MCv}$ & $6.9 \cdot 10^{19}$ & 1.3 \\
\hline & & $\mathrm{PCCV}$ & $6.6 \cdot 10^{19}$ & 1.5 \\
\hline \multirow[t]{4}{*}{ IA } & \multirow[t]{4}{*}{ CHIVAS-7 } & $\mathrm{T}$ & $6.6 \cdot 10^{19}$ & 2.6 \\
\hline & & $\mathrm{Cv}$ & $6.9 \cdot 10^{19}$ & 2.4 \\
\hline & & $\mathrm{MCV}$ & $6.9 \cdot 10^{19}$ & 1.3 \\
\hline & & $\mathrm{PCCV}$ & $6.7 \cdot 10^{19}$ & 2.1 \\
\hline \multirow[t]{4}{*}{ IAR } & \multirow{4}{*}{$\begin{array}{c}\text { CHIVAS-7 } \\
+ \\
\text { CHIVAS-8 }\end{array}$} & $\mathrm{T}$ & $1.3 \cdot 10^{20}$ & 2.2 \\
\hline & & $\mathrm{Cv}$ & $1.3 \cdot 10^{20}$ & 2.1 \\
\hline & & $\mathrm{MCv}$ & $1.3 \cdot 10^{20}$ & 2.1 \\
\hline & & $\mathrm{PCCV}$ & $1.3 \cdot 10^{20}$ & 2.2 \\
\hline
\end{tabular}

Note: IAR correspond to accumulated fluence of two irradiations.

It was observed that the maximum difference in fluence among specimen groups does not exceed $6 \%$, ${ }^{*}$ whereas considering individual specimens, due to the flux curvature, it can reach almost $25 \%$.

Heat Treatment Performed on IA and IAR Specimens. An annealing heat treatment was performed on specimens from the IA and IAR groups.

This consisted in $100 \mathrm{~h}$ at $\left(475_{-2}^{+4}\right)^{\circ} \mathrm{C}$, with a heating rate of $19^{\circ} \mathrm{C} / \mathrm{h}$ and a cooling rate of $30^{\circ} \mathrm{C} / \mathrm{h}$ (in the oven).

This annealing treatment was proven in the past to be the most effective in terms of Charpy-V transition temperature recovery for WWER-440 pressure vessel steels: the lower boundary $(-2 \sigma)$ of the recovery percentage is about $80 \%$ $[6,7]$.

Tensile Testing. Tensile tests have been performed in all material conditions, in accordance with ASTM E8M on sub-size cylindrical specimens with diameter $D=3 \mathrm{~mm}$ and reduced section length $L_{0}=14 \mathrm{~mm}$ (nominal dimensions). No extensometer was used to record specimen elongation.

All tensile strength values have been fitted using the following function:

$$
\sigma=\sigma_{a t h}+\sigma_{0} e^{\alpha T}
$$

where $\sigma_{\text {ath }}$ represents the athermal component, while $\sigma_{0}$ and $\alpha$ are fitting parameters.

\footnotetext{
* The consequences of such variations can be considered small: according to the Russian legislation, at such fluence levels $\left(6.5 \cdot 10^{19} \mathrm{n} / \mathrm{cm}^{2}\right)$ variations of $\pm 10 \%$ produce a change of $\pm 6^{\circ} \mathrm{C}$ in the (predicted) transition temperature shift.
} 
Yield stress values measured in the four different conditions (BL, I, IA, IAR) are compared in Fig. 1. Specific tensile test results can be found in [1-3].

We observed that:

(i) the annealing treatment produces a complete recovery of tensile properties with respect to the unirradiated condition;

(ii) tensile properties measured after irradiation and re-irradiation are equivalent, but for condition I are somewhat higher (hardening is slightly more pronounced);

(iii) trends are generally consistent both for the yield stress and the ultimate stress values.

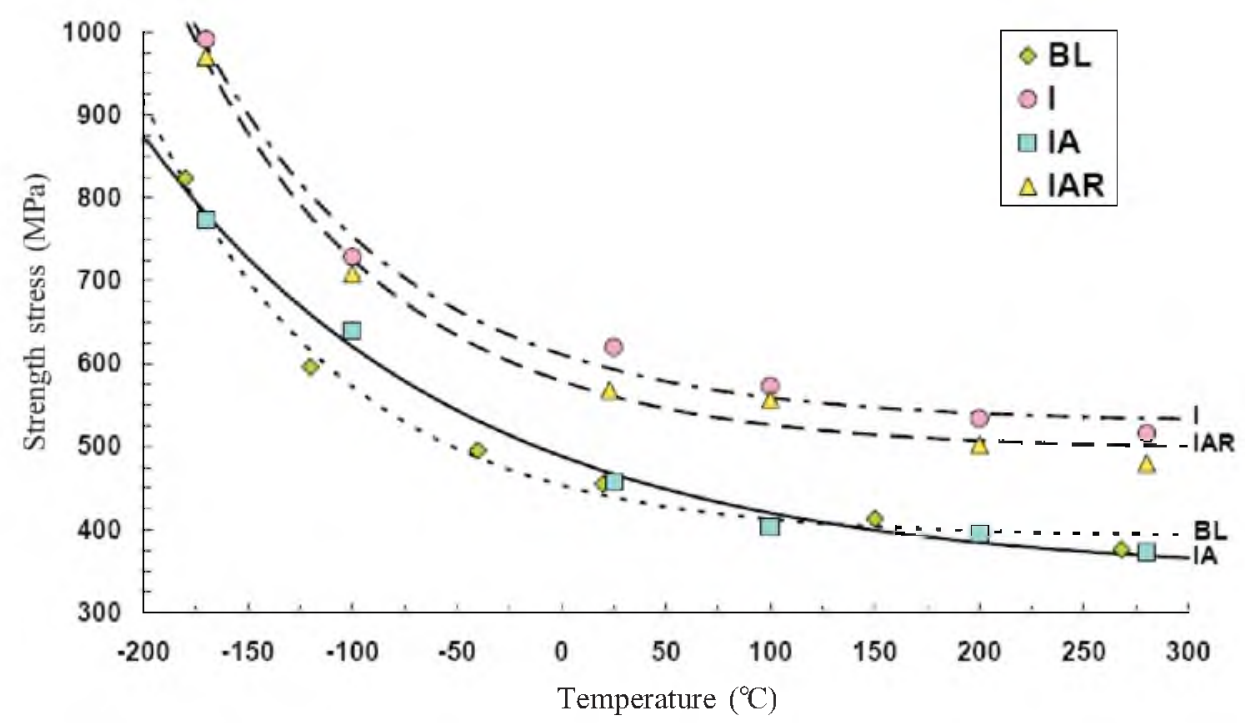

Fig. 1. Comparison of yield stress values measured in different conditions.

Standard Charpy-V Impact Testing. Impact tests have been performed in all material conditions, using a calibrated $300 \mathrm{~J}$ pendulum equipped with an instrumented DIN striker and a conditioning chamber which guaranteed a temperature stability of $\pm 2^{\circ} \mathrm{C}$. All tests have been carried out in accordance with ASTM E23 (striker geometry excluded) on full-size $(10 \times 10 \times 55 \mathrm{~mm})$ Charpy-V specimens. Specific data can be found in [1-3].

Index temperatures calculated from the impact transition curves obtained from the various specimen groups, including baseline, are compared in Table 2; these temperatures correspond to predefined values of dial energy $(41 \mathrm{~J}, 68 \mathrm{~J})$, SFA (50\%) and lateral expansion $(0.89 \mathrm{~mm})$, plus transition temperatures $T_{K}$ as defined in the Russian regulatory code [8]. Temperature shifts are normally used to quantify the variation of mechanical properties induced by neutron exposure or heat treatments (e.g., annealing).

Overall results in terms of dial energy are shown in Fig. 2.

We observed that:

- the shift of transition curves due to irradiation is higher than the shift caused by re-irradiation, while the relative decrease of upper shelf is more pronounced for re-irradiation (34\%) than for irradiation (26\%); 
- the annealing treatment substantially recovers the impact properties of the baseline condition in the transition region, while the upper shelf energy is significantly increased (31\%);

- the almost complete recovery in terms of transition temperature is in agreement with literature data on WWER-440 type steels (base and weld) for the same annealing conditions $[9,10]$;

- the embrittlement caused by re-irradiation is lower than for the irradiation, both in the transition region and in the upper shelf regime;

- the shifts of the transition temperature TK, calculated according to the Russian regulatory code, are in agreement with those of the "conventional" index temperatures.

$\mathrm{T}$ a b 1 e 2

Index Temperatures Measured on Full-Size Charpy Specimens in the Different Conditions Investigated, and Relevant Shifts Caused by Irradiation and/or Annealing

\begin{tabular}{|c|c|c|c|c|c|c|}
\hline Condition & $T_{41 \mathrm{~J}},{ }^{\circ} \mathrm{C}$ & $T_{68 \mathrm{~J}},{ }^{\circ} \mathrm{C}$ & USE, J & $T_{0.89 \mathrm{~mm}},{ }^{\circ} \mathrm{C}$ & $F A T T_{50},{ }^{\circ} \mathrm{C}$ & $T_{K},{ }^{\circ} \mathrm{C}$ \\
\hline BL & -6.5 & 13.0 & 119.1 & -3.4 & 12.8 & -8 \\
I & 111.7 & 148.9 & 88.5 & 123.4 & 115.2 & 124 \\
IA & -12.2 & 14.9 & 156.1 & -0.7 & 23.1 & -7 \\
IAR & 83.6 & 120.4 & 102.4 & 92.4 & 100.5 & 95 \\
\hline Shift & $\Delta T_{41 \mathrm{~J},{ }^{\circ} \mathrm{C}}$ & $\Delta T_{68} \mathrm{~J},{ }^{\circ} \mathrm{C}$ & $\Delta U S E, \mathrm{~J}$ & $\Delta T_{0.89 \mathrm{~mm},},{ }^{\circ} \mathrm{C}$ & $\Delta F A T T_{50},{ }^{\circ} \mathrm{C}$ & $\Delta T_{K},{ }^{\circ} \mathrm{C}$ \\
\hline $\mathrm{BL} \rightarrow \mathrm{I}$ & 118.2 & 135.9 & -30.6 & 126.8 & 102.4 & 132 \\
$\mathrm{I} \rightarrow$ LA & -123.9 & -134.0 & 67.6 & -124.1 & -92.1 & -131 \\
$\mathrm{BL} \rightarrow$ IA & -5.7 & 1.9 & 37.0 & 2.7 & 10.3 & -1 \\
IA $\rightarrow$ IAR & 95.8 & 105.5 & -53.7 & 93.1 & 70.4 & 102 \\
I $\rightarrow$ IAR & -28.1 & -28.5 & 13.9 & -31.0 & -21.7 & -29 \\
\hline
\end{tabular}

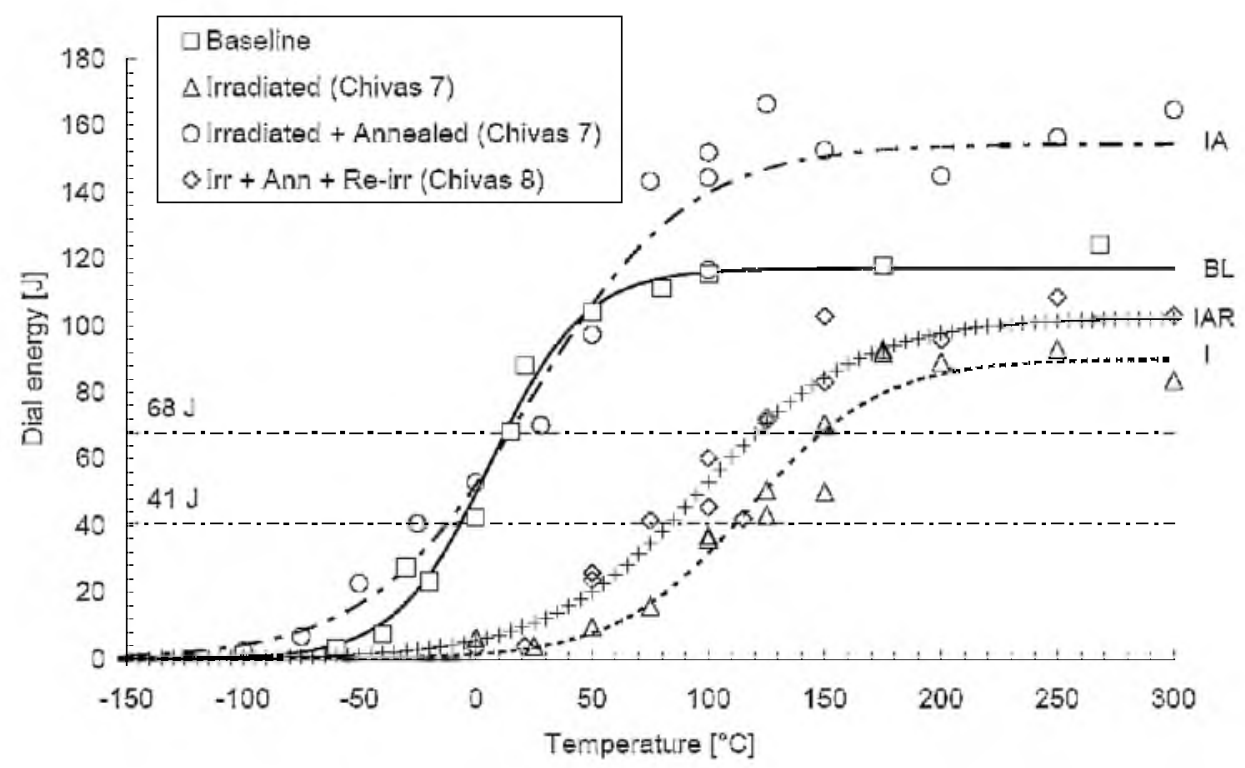

Fig. 2. Comparison of dial energy impact transition curves measured on full-size Charpy-V specimens in different conditions. 
Sub-Size Charpy-V Impact Testing. Sub-size impact tests have been performed in all material conditions, using a WOLPERT PW50 pendulum equipped with an instrumented DIN striker and a conditioning chamber which guaranteed a temperature stability of $\pm 2^{\circ} \mathrm{C}$. Test temperatures have been adjusted to account for the transfer time from the environmental chamber to the impact position, as described in $[2,11]$. Tests have been carried out on sub-size $(3 \times 4 \times 27 \mathrm{~mm})$ Charpy-V specimens; specific data can be found in [1-3].

Index temperatures calculated from the impact transition curves obtained from the various sub-size specimen groups, including baseline, are compared in Table 3 with relevant shifts; such temperatures correspond to predefined values of dial energy (1.9 J, $3.1 \mathrm{~J})$, SFA (50\%) and lateral expansion $(0.3 \mathrm{~mm})$. The $1.9 \mathrm{~J}$, $3.1 \mathrm{~J}$ and $0.3 \mathrm{~mm}$ levels for sub-size specimens correspond, respectively, to the $41 \mathrm{~J}, 68 \mathrm{~J}$ and $0.89 \mathrm{~mm}$ levels for full-size samples.

Overall results in terms of dial energy are shown in Fig. 3.

$\mathrm{T}$ a b 1 e 3

Index Temperatures Measured on Sub-Size Charpy Specimens in the Different Conditions Investigated, and Relevant Shifts Caused by Irradiation or Annealing

\begin{tabular}{|c|c|c|c|c|c|}
\hline Condition & $T_{1.9 \mathrm{~J},},{ }^{\circ} \mathrm{C}$ & $T_{3.1 \mathrm{~J}},{ }^{\circ} \mathrm{C}$ & $U S E, \mathrm{~J}$ & $T_{0.3 \mathrm{~mm},}{ }^{\circ} \mathrm{C}$ & $F A T T_{50},{ }^{\circ} \mathrm{C}$ \\
\hline BL & -57.2 & -46.7 & 6.0 & -57.3 & -42.9 \\
I & 7.8 & 29.7 & 4.4 & 13.9 & 16.9 \\
IA & -59.3 & -43.8 & 7.2 & -51.1 & -47.5 \\
IAR & 0.3 & 19.5 & 4.6 & 0.5 & 14.6 \\
\hline Shift & $\Delta T_{1.9 \mathrm{~J},{ }^{\circ} \mathrm{C}}$ & $\Delta T_{3.1 \mathrm{~J},{ }^{\circ} \mathrm{C}}$ & $\Delta U S E, \mathrm{~J}$ & $\Delta T_{0.3 \mathrm{~mm},{ }^{\circ} \mathrm{C}} \Delta F A T T_{50},{ }^{\circ} \mathrm{C}$ \\
\hline BL $\rightarrow$ I & 65.0 & 76.4 & -1.6 & 71.2 & 59.8 \\
I $\rightarrow$ IA & -67.1 & -73.5 & 2.8 & -65.0 & -64.4 \\
BL $\rightarrow$ IA & -2.1 & 2.9 & 1.2 & 6.2 & -4.6 \\
IA $\rightarrow$ IAR & 59.6 & 63.3 & -2.6 & 51.6 & 62.1 \\
I $\rightarrow$ IAR & -7.5 & -10.2 & 0.2 & 13.4 & -2.3 \\
\hline
\end{tabular}

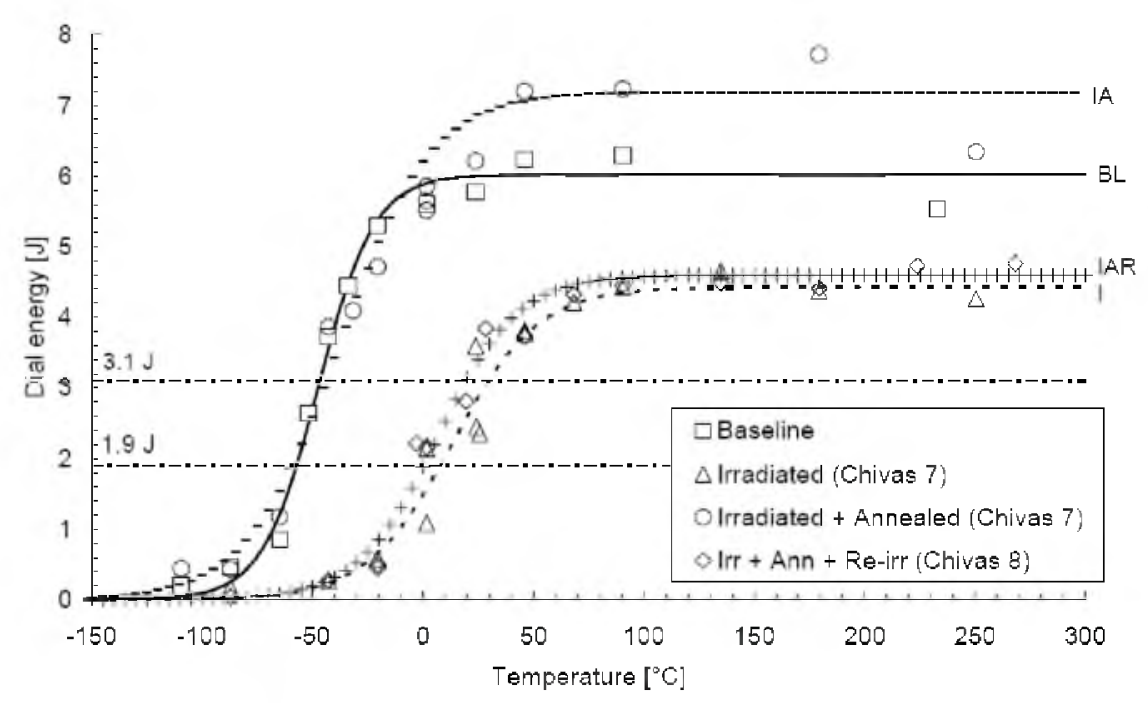

Fig. 3. Comparison of dial energy impact transition curves measured on sub-size Charpy-V specimens in different conditions. 
We observed that:

the shift of the transition curves due to irradiation is almost the same as that caused by re-irradiation, while the decrease of upper shelf is more pronounced for re-irradiation $(33 \%)$ than for irradiation $(27 \%)$;

the annealing treatment substantially recovers the toughness properties of the baseline condition in the transition region, with a significant improvement in the upper shelf energy (15\%), which is not observed for lateral expansion values;

the two irradiated conditions (I and IAR) appear to be almost identical, particularly in terms of SFA.

The first two observations confirm the data already obtained for full-size specimens.

Index Temperature Shifts Caused by Irradiation/Annealing Measured with Full-Size and Sub-Size Charpy-V Specimens. The variation of impact properties (index temperatures and USE) can be evaluated for the four conditions under examination considering both full-size and sub-size Charpy- $V$ specimens.

In absolute terms, index temperature shifts measured with sub-size specimens appear consistently lower than those yielded by full-size samples. This trend appears specific of the WWER-440 steel, since this trend has not been observed on other pressure vessel steels, characterized at SCK-CEN using full-size and sub-size Charpy specimens [11] (Fig. 4).

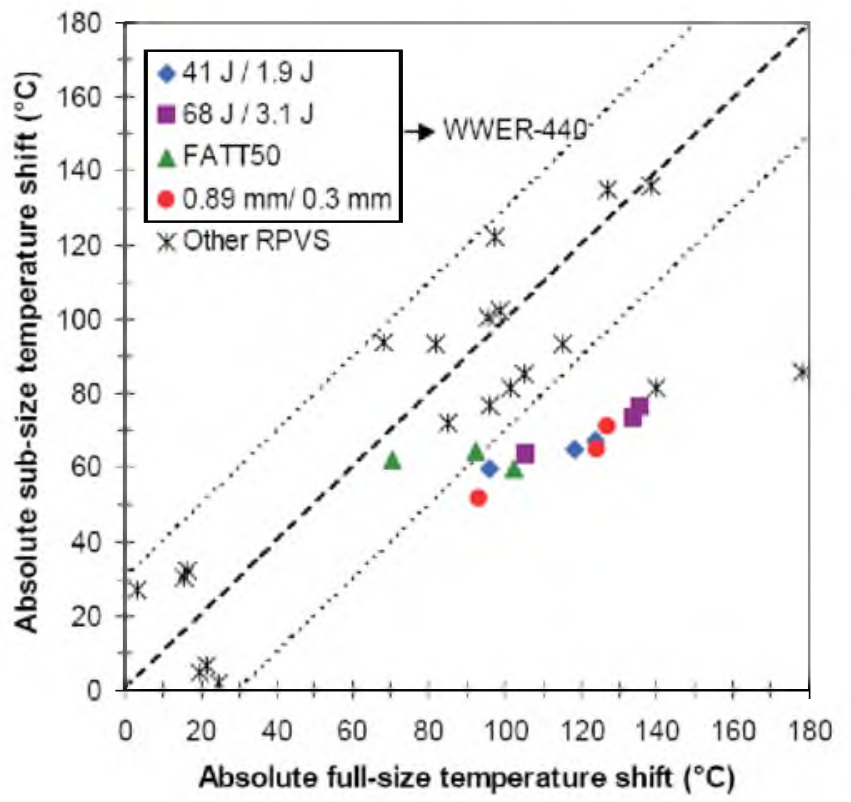

Fig. 4. Comparison of the absolute index temperature shifts measured using full-size and sub-size Charpy-V specimens, for the WWER-440 steel and with respect to other RPVS.

Fracture Toughness Testing. Fracture toughness tests have been performed in all material conditions, using a certified INSTRON universal machine and a PID-controlled chamber which guarantees a temperature stability of $\pm 0.5^{\circ} \mathrm{C}$ measured on the specimen. 
Tests have been carried out on fatigue precracked and 20\% side-grooved Charpy-V specimens, instrumented with clip-gage for the measurement of CMOD (Crack Mouth Opening Displacement). Toughness data have been analyzed according to the Master Curve methodology given in the ASTM E1921-97 standard, in order to establish the reference temperature $T_{0}$ corresponding to a median toughness $K_{J c(\text { med })}=100 \mathrm{MPa} \sqrt{\mathrm{m}}$ for the $1 \mathrm{TCT}$ reference specimen geometry. Specific test results can be found in $[2,3]$.

Reference temperature values and their standard deviations are given for all conditions in Table 4.

$\mathrm{T}$ a b 1 e 4

Reference Temperatures with Standard Deviation

\begin{tabular}{|c|c|c|}
\hline Condition & $T_{0},{ }^{\circ} \mathrm{C}$ & $\sigma,{ }^{\circ} \mathrm{C}$ \\
\hline BL & -33 & 5 \\
\hline I & 66 & 7 \\
\hline IA & -21 & 7 \\
\hline IAR & 58 & 7 \\
\hline
\end{tabular}

All test results, normalized to 1TCT, from the different conditions are uniquely represented in Fig. 5 as a function of the difference between test temperature and $T_{0}$ with Master Curve and different confidence bounds $(1 \%$, $5 \%, 95 \%, 99 \%)$.

Figure 5 shows that the Master Curve methodology can effectively represent the transitional behavior of the WWER-440 weld material in different conditions.

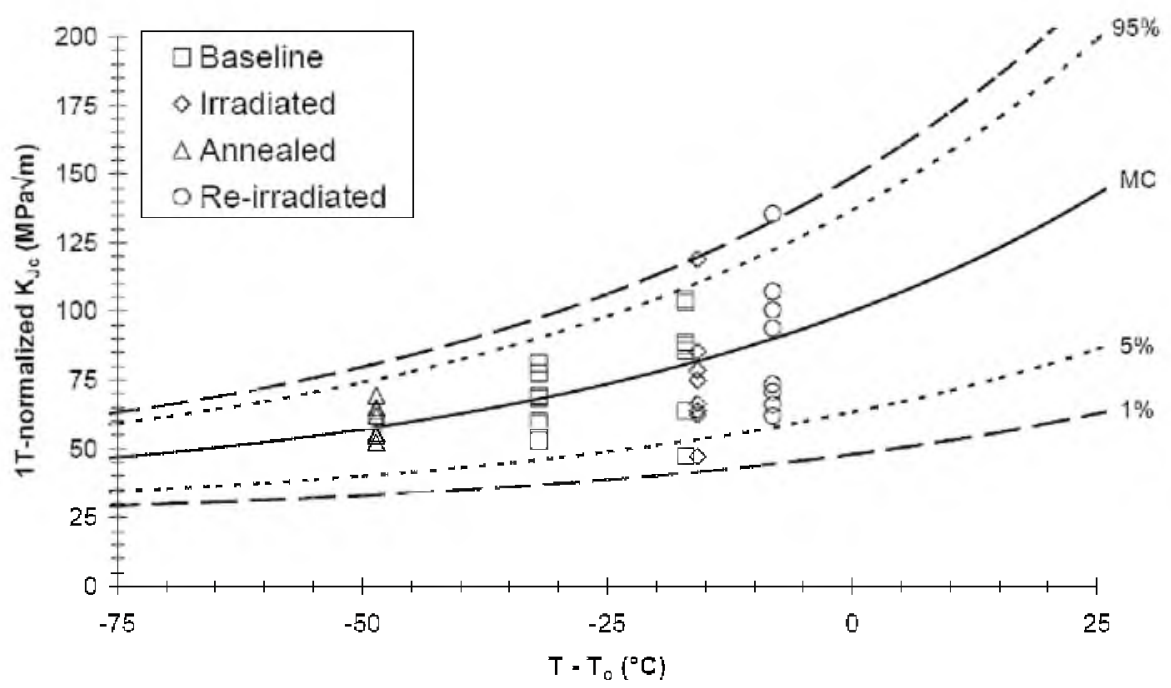

Fig. 5. Results of the toughness tests performed in different material conditions.

If we compare temperature shifts caused by irradiation, annealing and re-irradiation measured in terms of impact parameters (energy, SFA, lateral expansion, and $T_{K}$ ) and fracture toughness $\left(T_{0}\right)$, we observe that $T_{0}$ shifts are 
significantly smaller than those of the $41 \mathrm{~J}, 68 \mathrm{~J}, 0.89 \mathrm{~mm}$ or $T_{K}$ temperatures, being in a good agreement (within $10^{\circ} \mathrm{C}$ ) with the shifts of the $F A T T_{50}$ temperature. This circumstance was previously observed at SCK-CEN on other pressure vessels steels, in terms of both static and dynamic fracture toughness [12]. Furthermore, $T_{K}$ shifts are in better agreement with $T_{68 \mathrm{~J}}$ than with $T_{41 \mathrm{~J}}$ shifts.

Comparisons with Regulatory Lower Bound Curves. Master Curves corresponding to low cleavage fracture probabilities (typically, $1 \%$ or $5 \%$ ), obtained in the various conditions, can be compared with toughness lower bound curves given by various national regulatory codes. The latter represent, for reactor pressure vessel steels, the lower limit of fracture toughness as a function of temperature, normalized to a predefined reference transition temperature.

In this study, $K_{\text {Ic }}$ lower bound curves given by the Russian legislation [8] and by the ASME code [13], widely used for Western reactor pressure vessel steels, have been considered.

In the Russian regulatory code [8], three different static initiation toughness curves are given, corresponding to different operating conditions: normal conditions, upset and test conditions, and emergency conditions. The last one (emergency conditions), corresponding to the lowest toughness level, can be used as a lower bound curve; its expression for weld materials is the following:

$$
K_{\mathrm{Ic}}=35+53 e^{0.0217\left(T-T_{K}\right)} .
$$

On the other hand, the equation of the ASME lower bound curve (to be used for the following steels: SA 533B Cl.1-, SA $508 \mathrm{Cl} .2-$, and SA 508 Cl.3-base materials and welds), is

$$
K_{\mathrm{Ic}}=36.48+22.783 e^{0.036\left(T-R T_{\mathrm{NDT}}\right)},
$$

where, in the baseline condition, the Reference Temperature for Nil Ductility Transition $\left(R T_{\mathrm{NDT}}\right)$ is defined as the minimum of:

- $T_{\mathrm{NDT}}$, measured by Pellini drop-weight tests in accordance with ASTM E208-95a;

- $T_{\mathrm{Cv}}-33^{\circ} \mathrm{C}$, where $T_{\mathrm{Cv}}$ is the highest of the Charpy $T_{68 \mathrm{~J}}$ and $T_{0.89 \mathrm{~mm}}$ temperatures.

In the absence of Pellini tests, the initial $R T_{\mathrm{NDT}}$ for the baseline condition may be determined from Charpy tests alone; in our case: $R T_{\mathrm{NDT}(\mathrm{BL})}=-20^{\circ} \mathrm{C}$.

The effect of irradiation or annealing on the toughness curves is evaluated indirectly, by shifting the curves by an amount equal to the shift of $T_{41} \mathrm{~J}$ from Charpy tests; in our case:

$$
\begin{aligned}
& R T_{\mathrm{NDT}(\mathrm{I})}=R T_{\mathrm{NDT}(\mathrm{BL})}+\Delta T_{41 \mathrm{~J}(\mathrm{BL} \rightarrow \mathrm{I})}=98^{\circ} \mathrm{C}, \\
& R T_{\mathrm{NDT}(\mathrm{IA})}=R T_{\mathrm{NDT}(\mathrm{BL})}+\Delta T_{41 \mathrm{~J}(\mathrm{BL} \rightarrow \mathrm{IA})}=-26^{\circ} \mathrm{C}, \\
& R T_{\mathrm{NDT}(\mathrm{IAR})}=R T_{\mathrm{NDT}(\mathrm{BL})}+\Delta T_{41 \mathrm{~J}(\mathrm{BL} \rightarrow \mathrm{IAR})}=70^{\circ} \mathrm{C} .
\end{aligned}
$$


Using 1TCT-normalized fracture toughness data, the comparison between the $1 \%$ and $5 \%$ fracture probability Master Curves and the Russian and ASME lower bound curves is given in Fig. 6 (baseline/irradiated), Fig. 7 (irradiated/ annealed) and Fig. 8 (annealed/re-irradiated).

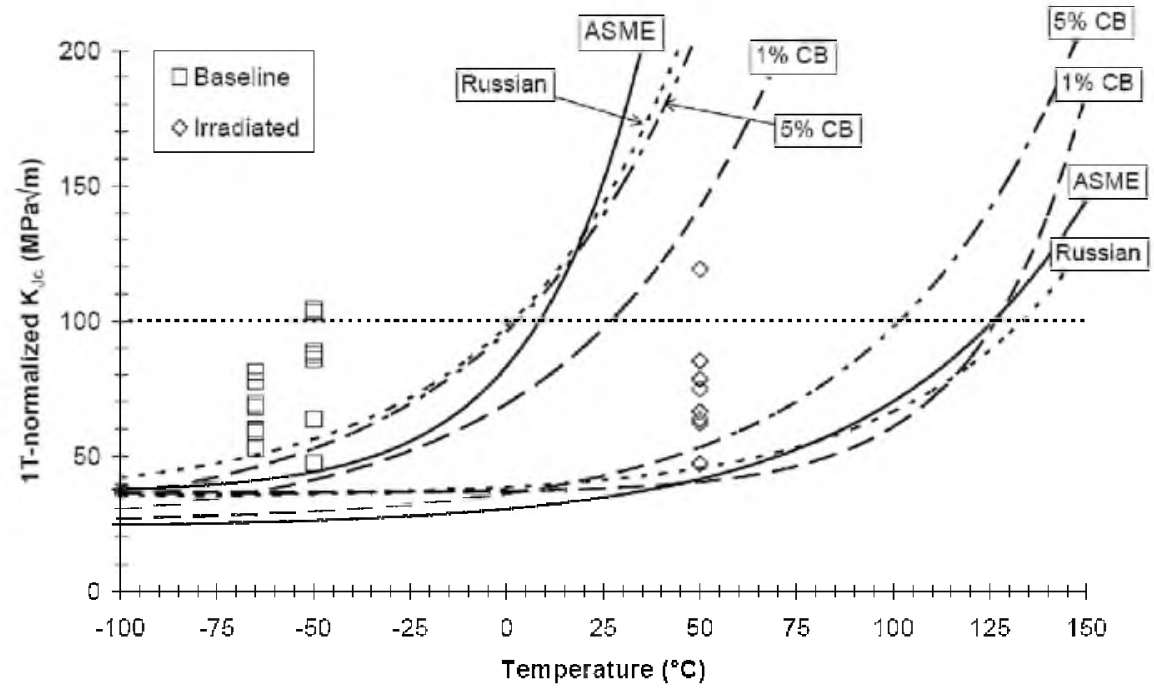

Fig. 6. Comparison of the 5\% and 1\% fracture probability Master Curves and regulatory lower bound curves for the baseline and irradiated conditions.

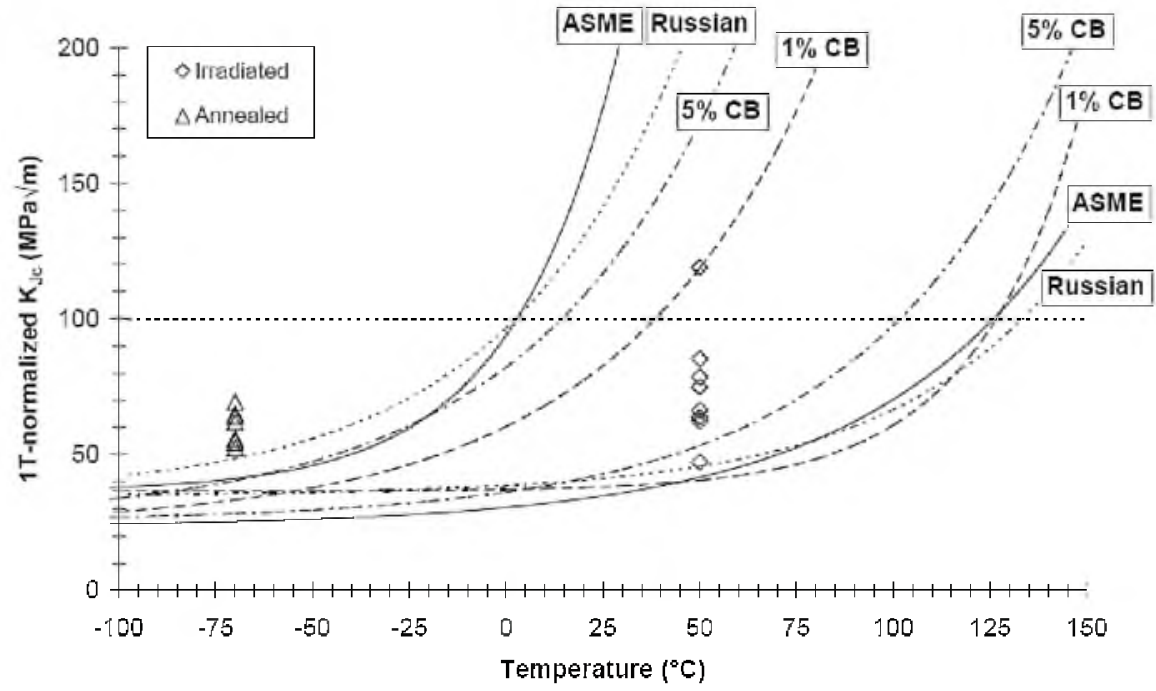

Fig. 7. Comparison of the $5 \%$ and $1 \%$ fracture probability Master Curves and regulatory lower bound curves for the irradiated and annealed conditions.

In different conditions, only the ASME curve and 1\% Master Curve provide an effective lower bound to all the toughness values measured at the respective test temperatures.

The Master Curve corresponding to $1 \%$ fracture probability results are too conservative in the $\mathrm{BL}$ and IA condition; while in condition $\mathrm{I}$, the $5 \%$ fracture probability Master Curve is strongly non-conservative. 


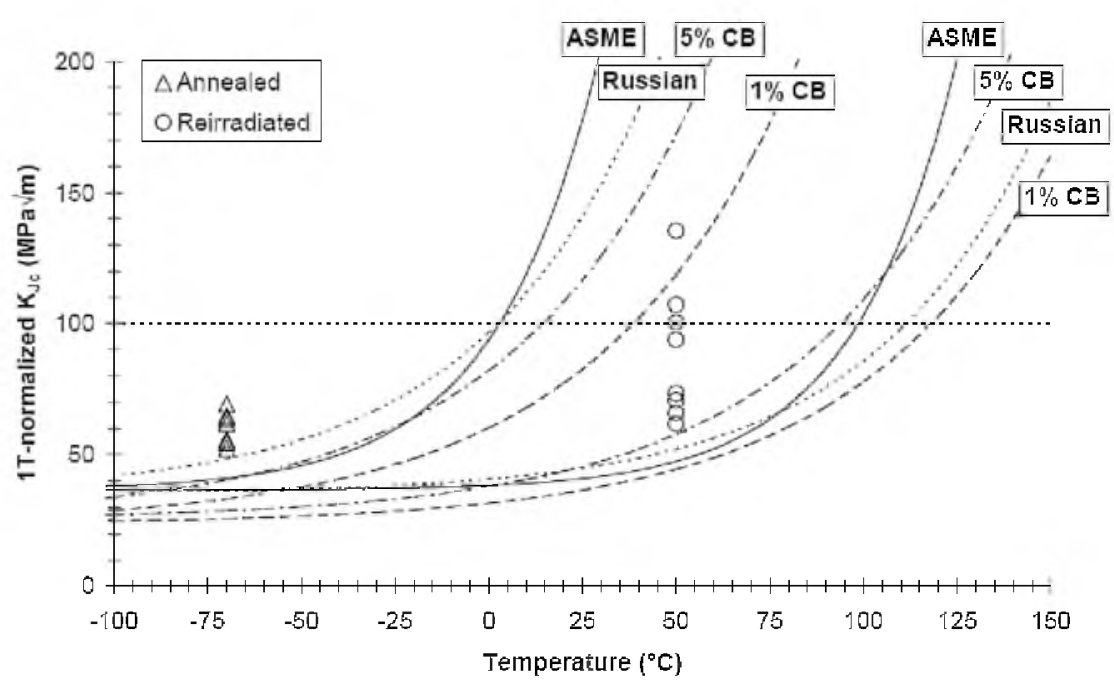

Fig. 8. Comparison of the 5\% and 1\% fracture probability Master Curves and regulatory lower bound curves for the annealed and re-irradiated conditions.

\section{Evaluation of Material Behavior under Irradiation.}

Transition Temperature Shifts. Various correlations are available for predicting radiation-induced transition temperature shifts, based on fast neutron fluence, chemical composition and other parameters; an extensive review is given in [14].

The Russian correlation has been considered in this study for comparison with temperature shifts experimentally measured for irradiation and re-irradiation.

The predictive formula used to evaluate the effect of irradiation takes into account the contents of $\mathrm{Cu}$ and $\mathrm{P}$, as well as the fluence. The analytical expression is

$$
\Delta T_{K}=A_{F}\left(\frac{\phi}{10^{22}}\right)^{1 / 3}
$$

where $\phi$ is the neutron fluence (measured in $10^{22} \mathrm{n} / \mathrm{m}^{2}, E>0.5 \mathrm{MeV}$ ) and in the case of welds $\left(T_{i r}=270^{\circ} \mathrm{C}\right)$ :

$$
A_{F}=800(\mathrm{P}+0.07 \mathrm{Cu})
$$

Since the fluence is normally given in units of $10^{19} \mathrm{n} / \mathrm{cm}^{2}, E>1 \mathrm{MeV}$, the following equivalence has been proposed [14]:

$$
\phi \text { in } 10^{22} \mathrm{n} / \mathrm{m}^{2}, E>0.5 \mathrm{MeV} \leftrightarrow 18 \phi \text { in } 10^{19} \mathrm{n} / \mathrm{cm}^{2}, E>1 \mathrm{MeV} \text {, }
$$

which finally leads to

$$
\Delta T_{K}=800(\mathrm{P}+0.07 \mathrm{Cu})\left(\frac{18 \phi}{10^{19}}\right)^{1 / 3} .
$$


This formula is supposed to provide an upper bound to the transition temperature shift.

The calculated shifts of transition temperatures, both in terms of impact $\left(T_{K}\right.$, $\left.T_{41 \mathrm{~J}}\right)$ and toughness $\left(T_{0}\right)$ properties, measured as a consequence of irradiation (CHIVAS-7) and re-irradiation after annealing (CHIVAS-8), are compared in Fig. 9 with the prediction given by the above formula. Although not fully relevant, the results obtained with the US Regulatory Code [15] and NUREG refined correlation [16] are also plotted in Fig. 9.

For the CHIVAS-8 campaign, the reference condition is, in this case, the annealed (IA) condition, while only the fluence accumulated in the second irradiation (and not the total accumulated fluence) is taken into account.

Figure 9 shows that the experimentally measured shifts are underestimated by the E900 correlation and overestimated by the 'conservative' Russian and NUREG formulas.

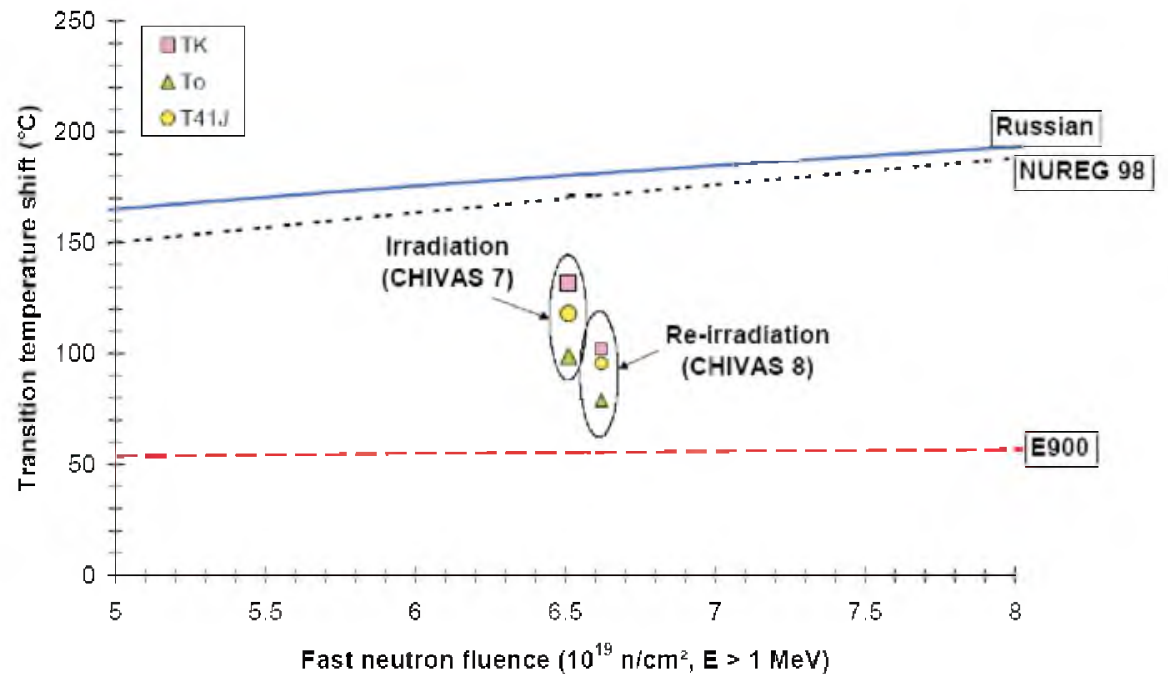

Fig. 9. Comparison of measured and predicted transition temperature shifts.

Upper Shelf Energy Degradation. In the Russian and US regulatory codes, no predictive formulas are given for evaluating the decrease in USE as a consequence of neutron irradiation.

However, in the previously mentioned NUREG report [16], a correlation is proposed for the prediction of the Charpy Upper Shelf Energy of the irradiated material $\left(U S E_{i}\right)$, as a function of:

- USE of the unirradiated condition $\left(U S E_{u}\right)$;

- product form;

- $\mathrm{Cu}, \mathrm{Ni}$ and P contents;

- fast neutron fluence $(\phi)$.

The correlation has the form

$U S E_{i}=-0.057 U S E_{u}^{1.456}+\Gamma-\left[17.5 f(\mathrm{Cu})\left(1+1.17 \mathrm{Ni}^{0.8894}\right)+305 \mathrm{P}\right]\left(\frac{\phi}{10^{19}}\right)^{0.2223}$ 
with

$$
f(\mathrm{Cu})=\frac{1}{2}+\frac{1}{2} \tanh \left(\frac{\mathrm{Cu}-0.138}{0.0846}\right) .
$$

All USE values are in $\mathrm{ft}-\mathrm{lb}$ and the constant $\Gamma$ is 55.4 for welds, 61.0 for plates and 66.3 for forgings. The reported standard error of the model is $15 \mathrm{~J}$.

For the material under examination, the results given in Table 5 have been obtained. Once again, for the IAR condition the USE of the IA state was taken as a reference.

$\mathrm{T}$ a b 1 e 5

Comparison between Predicted and Measured USE Values for the I and IAR Conditions

\begin{tabular}{|c|c|c|c|}
\hline Condition & $U S E_{i}^{\text {pred }}, \mathrm{J}$ & $U S E_{i}^{\text {meas }}, \mathbf{J}$ & $\Delta U S E^{\text {pred-meas }}, \mathrm{J}$ \\
\hline I & 85.0 & 88.5 & -3.5 \\
\hline IAR & 110.0 & 102.4 & 7.6 \\
\hline
\end{tabular}

In both cases, predictions are in close agreement with measured values. In principle this is coincidental, as the NUREG formula is not 'based' on Russian steel. However, as the transition temperature shift predictions between Russian and NUREG codes also coincide, the correspondence might have a more fundamental explanation.

Recovery of Material Toughness Due to Annealing. The key elements with respect to continued operation of a reactor vessel after annealing are the degree of recovery and the re-embrittlement trend.

For WWER-440 reactor pressure vessel steels, $475^{\circ} \mathrm{C}$ is nowadays used as annealing temperature. Investigations done with base and weld materials, irradiated both in power and test reactors, have shown that the difference between annealing $\left(T_{a n n}\right)$ and irradiation $\left(T_{i r r}\right)$ temperatures correlates well with the percentage of recovery $(\eta)$, while differences in the chemical composition seem to play a minor role $[9,10]$.

The following empirical correlations have been reported for WWER-440 RPV steels:

$$
\begin{gathered}
\eta=0.494\left(T_{a n n}-T_{i r r}\right)+2.44, \\
\eta=0.472\left(T_{a n n}-T_{i r r}\right)+5.8 .
\end{gathered}
$$

In this study, $\left(T_{a n n}-T_{i r r}\right)=207^{\circ} \mathrm{C}$. Both formulas give $\eta>100 \%$, which agrees well with the measured recovery in terms of impact properties $\left(T_{K}\right.$ and $T_{41 \mathrm{~J}}$, $\eta=99-100 \%)$. The recovery in terms of fracture toughness $\left(T_{0}\right)$ is however slightly inferior $(\eta=88 \%)$

In terms of Upper Shelf Energy recovery, recent studies [17] have shown that USE often over-recovers as a consequence of annealing; this may also explain why the USE value after re-irradiation might not decrease significantly with respect to the unirradiated condition. 
These assumptions are in good agreement with the results presented in this study, since the degree of USE recovery after annealing corresponds to $131 \%$ and the USE after re-irradiation is $86 \%$ of the unirradiated (baseline) value.

Evaluation of Re-Irradiation Embrittlement. Data from studies conducted on Western and Eastern (WWER-type) pressure vessel steels suggest that the re-embrittlement rate (consequent to re-irradiation after annealing) is the same or lower than in the original irradiation [18-21].

Since the available data base of annealing recovery and re-embrittlement trend does not cover all material and annealing conditions, several assumptions have been made in developing a trend curve approach.

The ASTM E509-97 standard, for instance, proposes two methodologies for developing a post-annealing re-irradiation trend curve:

1. The "lateral shift methodology": the initial irradiation (I) embrittlement path (given by one of the predictive formulas previously discussed) is shifted laterally at the ordinate corresponding to the annealed (IA) condition, in order to become the post-anneal re-irradiation trend curve for the irradiated-annealedre-irradiated (IAR) condition. This approach postulates that re-irradiation embrittlement follows the same rate as in the initial embrittlement stage at the same horizontal level.

2. The "vertical shift methodology": a portion of the initial irradiation trend, projected as re-irradiation behaviour, is translated down vertically at the abscissa corresponding to the irradiated (I) and annealed (IA) conditions. This way, the re-embrittlement rate is supposed to follow the original embrittlement path as if annealing had no influence. $[18,22]$ :

In addition, a third methodology has been proposed and applied in Russia

3. The "conservative shift methodology": the re-irradiation embrittlement rate is supposed to follow the shape of the initial embrittlement curve from a zero fluence point (origin). If annealing recovery is complete (as in the case of the present study), this approach becomes identical to the lateral shift method.

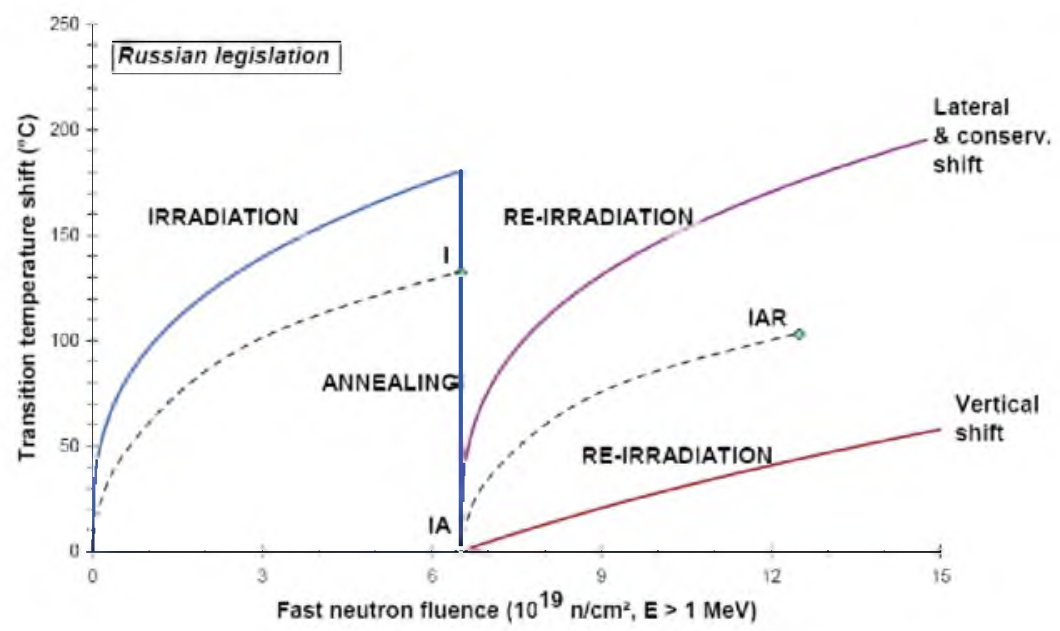

Fig. 10. Experimental shifts of transition temperature $T_{K}$ compared to theoretical predictive models (based on the Russian legislation), represented by solid lines; dashed curves are trend-lines connecting experimental points. 
Using the embrittlement correlation given in the Russian regulatory code, Fig. 10 provides comparison of the experimental results with the three predictive methodologies described above.

We observe that:

- irradiation embrittlement is inferior to that predicted by the Russian legislation, as previously observed;

- re-irradiation embrittlement is higher than predicted by the vertical shift method, but significantly less than according to the lateral and conservative shift approaches;

- however, from a qualitative point of view (see dashed lines in Fig. 10), the re-embrittlement rate appears to be lower than the embrittlement rate.

Conclusions. An overview has been given of SCK-CEN contribution to the IAEA Round-Robin Exercise on WWER-440 RPV Weld Material Irradiation, Annealing and Re-Embrittlement.

Specifically, the following activities have been addressed:

- irradiation of WWER-440 specimens in the CHIVAS-7 campaign in BR2;

- annealing heat treatment of one group of specimens;

- re-irradiation of another group of specimens in the CHIVAS-8 campaign;

- tensile, instrumented impact and fracture toughness tests on BL (baseline), (irradiated), IA (irradiated+annealed) and IAR (irradiated+annealed+ re-irradiated) specimen groups.

Comparison of different specimen groups have been made in terms of mechanical properties using different approaches (both conventional and more refined ones).

The most significant findings can be summarized as follows.

1. Tensile tests:

- annealing produces a complete recovery of tensile strength;

- re-irradiation causes a slightly inferior hardening as compared to irradiation.

2. Impact tests:

- the transition curve shift caused by irradiation is higher than that obtained for re-irradiation of full-size specimens, but is almost identical to that for sub-size specimens;

- annealing recovers the properties of the baseline condition, with a significant increase of upper shelf energy;

- temperature shifts induced by irradiation, annealing or re-irradiation, measured by full-size tests, are consistently underestimated by sub-size test results.

3. Fracture toughness tests:

- although the reference temperature measured in the IA condition is higher than for the BL condition, however the two respective values of $T_{0}$ cannot be considered different from a statistical point of view;

- similarly, the reference temperature shift caused by re-irradiation is lower than that in the case of irradiation, but the two values of $\Delta T_{0}$ are statistically equivalent;

- the Master Curve methodology with its associated confidence bounds gives a satisfactory representation of the fracture toughness for all examined conditions in the transition range; 
- $\Delta T_{0}$ shifts are generally lower than the corresponding shifts of the most Charpy index temperatures, although the agreement with $\triangle F A T T_{50}$ is very good;

- Master Curves associated to low fracture probabilities (1\%, 5\%) have been compared with regulatory lower bound toughness curves (Russian, ASME).

4. In terms of neutron embrittlement, the measured transition temperature shifts for irradiation and re-irradiation are underestimated by the present formulation of ASTM E900-87(94) and overestimated by the Russian legislation formula and by an improved correlation proposed by NUREG in more recent years.

5. The complete recovery observed is in agreement with literature data for similar materials and annealing conditions.

6. The re-embrittlement rate following re-irradiation after annealing appears lower than the embrittlement rate from the baseline condition.

To summarize in a concise form the effects of annealing and re-irradiation which have been observed in this work, the following can be stated:

- annealing produces a complete recovery of mechanical properties after irradiation, with a significant increase in USE;

- the embrittlement caused by re-irradiation after annealing is inferior to the initial toughness degradation induced by irradiation.

Acknowledgements. The authors acknowledge contribution of the technical staff of LHMA, TCH and BR2 departments to this activity, and more specifically to $\mathrm{W}$. Claes and his team for dismantling, to R. Mertens for specimen preparation and to L. Van Houdt, J. Veraghtert, and R. Vosch for testing.

\section{Резюм е}

Досліджуються механічні характеристики зварних з'єднань корпусів реакторів ВВЕР-440 з урахуванням різного стану: початкового (неокрихчуваного), після радіаційного окрихчування з середньою густиною потоку нейтронів до $6,5 \cdot 10^{19}$ нейтр/см ${ }^{2}$, окрихчуваного 3 наступним відпалом, повторно окрихчуваного 3 флюенсом частинок $1,3 \cdot 10^{20}$ нейтр/см ${ }^{2}$. Для кожного стану матеріалу проведено дослідження на розтяг, ударне руйнування та тріщиностійкість із використанням зразків Шарпі (стандартні, відновлені та 3 попередньо нанесеною тріщиною).

1. E. van Walle et al., SCK-CEN Contribution to the IAEA Round Robin Exercise on WWER-440 RPV Weld Material Irradiation, Annealing, and Re-Embrittlment, SCK-CEN Report BLG-768 (1998).

2. E. van Walle et al., SCK-CEN Contribution to the IAEA Round Robin Exercise on WWER-440 RPV Weld Material Irradiation, Annealing, and Re-Embrittlement, 2nd Progress Report, SCK-CEN Report BLG-827 (1999).

3. E. Lucon et al., SCK-CEN Contribution to the IAEA Round Robin Exercise on WWER-440 RPV Weld Material Irradiation, Annealing, and Re-Embrittlment, SCK-CEN Final Report BLG-845 Rev 1 (2000). 
4. Investigation Results Report - Weld, No. 502 Certification, MOHT-OTJIG RM and EDO, Gidropress (1997).

5. IAEA Round Robin Exercise on WWER-440 RPV Weld Material Irradiation, Annealing, and Re-Embrittlement: Terms of Reference, IAEA TC Project RER/9/035 WWER-SC-192 (1996).

6. M. Brumovsky, P. Novosad and M. Vacek, "Material properties of Bochunice 1 and 2 reactor pressure vessel materials before and after annealing," in: International Workshop on WWER-440 Reactor Pressure Vessel Embrittlement and Annealing, Zavazna Poruba (29-31 March), Slovak Republic (1994).

7. R. Pelli and K. Torronen, State of the Art Review on Thermal Annealing, AMES Report No. 2, EUR 16278 EN (1995).

8. PNAE-G-7-002-86. Calculation Standard for Strength of Equipment and Pipes of Nuclear Power Units [in Russian], Énergoatomizdat, NGA-01-85-1, NIKIET (1989).

9. A. D. Amaev et al., "Study of mechanical properties recovery processes of irradiated pressure vessel steels at annealing," in: Radiation Materials Science [in Russian], Vol. 4, Kharkov, pp. 25-32.

10. V. A. Ignatov et al., "Annealing of irradiation embrittlement of reactor pressure vessel material in Novovoronezh 1 NPP," in: Joint Seminar on Irradiation Embrittlement of Reactor Pressure Vessels (Cologne, Sep. 3-7) (1990).

11. E. Lucon et al., Correlations between Standard and Miniaturized Charpy-V Specimens, SCK-CEN Report BLG-797 (1998).

12. E. Lucon and R. Chaouadi, "Radiation damage assessment by the use of dynamic toughness measurements on pre-cracked Charpy-V specimens", in: Effects of Radiation on Materials (20th Int. Symp.); S. T. Rosinski, M. L. Grossbeck, T. R. Allen, and A. S. Kumar (Eds.), ASTM STP 1405, West Conshohocken, PA (2002).

13. ASME Boiler and Pressure Vessel Code, Section II (1995).

14. P. Petrequin, A Review of Formulas for Predicting Irradiation Embrittlement of Reactors Vessel Material, AMES Report No. 5, EUR 16455 EN (1996).

15. P. N. Randall, "Basis for revision 2 of U.S. NRC Regulatory Guide 1.99," in: Radiation Embrittlement of Nuclear Reactor Pressure Vessel Steels, ASTM STP 909 (1986), pp. 149-162.

16. E. D. Eason, J. E. Wright, and G. R. Odette, Improved Embrittlement Correlations for Reactor Pressure Vessel Steels, NUREG/CR-6551, MCS 970501 (1998).

17. S. K. Iskander et al., "Re-irradiation response rate of a high-copper reactor pressure vessel weld," presented at the 20th ASTM Symposium on the Effect of Radiation on Materials (Williamsburg Virginia, June 6-8) (2000).

18. A. D. Amaev, A. M. Kryukov, and M. A. Sokolov, "Recovery of the transition temperature of irradiated WWER-440 vessel material by annealing," in: Radiation Embrittlement of Nuclear Reactor Pressure Vessel Steels, ASTM STP 1170, 1193 (1992), pp. 369-379. 
19. T. R. Mager, "Thermal annealing of an embrittled reactor vessel: feasibility and methodology," in: Nuclear Engineering and Design, Vol. 124 (1990), pp. $43-51$.

20. J. R. Hawthorne, H. E. Watson, and F. J. Loss, Experimental investigation of multi cycle irradiation and annealing effects on notch ductility of A533-B weld deposits, in: ASTM STP 725 (1981).

21. A. M. Kryukov and M. A. Sokolov, "Investigation of material behavior under rerradiation after annealing using subsize specimens," in: Small Specimen Test Techniques Applied to Nuclear Reactor Vessel Thermal Annealing and Plant Life Extension, ASTM STP 1204 (1993), pp. 417-423.

22. Reactor Pressure Vessel Embrittlement. Report of the IAEA Extrabudgetary Programme on the Safety of WWER-440 Model 230 Nuclear Power Plants, IAEA-TECDOC-659 (1992). 